\title{
EVALUACIÓN DE NIVELACIÓN Y LA ENSEÑANZA DE LENGUAS ADICIONALES EN EL CONTEXTO UNILA
}

\author{
Florencia Páez ${ }^{69}$ \\ Laura Márcia Luiza Ferreira ${ }^{70}$
}

RESUMEN: El análisis de evaluaciones de lenguas adicionales retroalimentan reflexiones sobre la enseñanza en diferentes contextos. El presente trabajo tiene como objetivo de investigación las pruebas de nivelación de portugués como lengua adicional realizadas en la Universidad Federal de Integración Latinoamericana (UNILA). Forman parte del corpus 10 tareas de producción textual aplicadas durante el periodo de 2014-2017. Con la finalidad de analizar el contenido de las pruebas y compararlas a lo largo de las ediciones estudiadas, utilizamos como principales categorías de análisis las nociones de género textual, dominio discursivo y soporte de los textos de lectura de las pruebas, así como el análisis de los propósitos y de los géneros textuales delimitados en las consignas de las tareas. Al final, podemos inferir a partir del análisis, que las tareas de las pruebas se tornaron gradualmente más complejas a medida en que las prácticas sociales del lenguaje, simuladas por medio de las tareas, fueron aproximándose al contexto académicoinstruccional. Fue posible también levantar informaciones sobre los criterios de dispensa materializados en las propuestas de pruebas para el debate sobre su relación con la enseñanza de portugués como lengua adicional en el contexto universitario analizado.

Palabras clave: Enseñanza de portugués como lengua adicional; Evaluación en lenguas adicionales; UNILA; Géneros textuales.

RESUMO: A análise de avaliações de línguas adicionais retroalimentam reflexões sobre o ensino em diferentes contextos. O presente trabalho tem como objeto de investigação as provas de nivelamento de português como língua adicional realizadas na Universidade Federal da Integração

${ }^{69}$ Bolsista de Iniciação Científica da Universidade Federal da Integración Latinoamericana-UNILA.

${ }^{70}$ Doutora em Estudos de Linguagens pelo Programa de Pós-graduação do Cefet-MG. Professora da Universidade Federal da Integração LatinoAmericana-UNILA. 
Latinoamericana (UNILA). Faz parte do corpus 10 tarefas de produção de texto aplicadas durante o período de 2014 a 2017. Com a finalidade de analisar o conteúdo das provas e compará-los ao longo das edições estudadas, utilizamos como principais categorias de análise as noções de gênero textual, domínio discursivo e suporte dos textos de leitura das provas, bem como a análise dos propósitos e dos gêneros textuais delimitados nos comandos das tarefas. Ao final, pudemos inferir a partir da análise que as tarefas das provas foram gradativamente se complexificando na medida em que as práticas sociais de linguagem simuladas por meio das tarefas foram se aproximando do contexto acadêmico-instrucional. Foi possível também levantar informações sobre os critérios de dispensa materializados nas propostas de prova para o debate sobre sua relação com o ensino de português como língua adicional no contexto universitário analisado.

Palavras-chave: Ensino de português como língua adicional; Avaliação em línguas adicionais, UNILA, Gêneros textuais.

\section{Introducción}

La Universidad Federal de Integración Latinoamericana (UNILA), fue fundada en el año 2010 y ubicada estratégicamente en la ciudad de Foz do Iguaçu - PR - triple frontera entre Argentina, Brasil y Paraguay - , donde existe un escenario multilingüe y multicultural, favoreciendo el dialogo y la interacción regional. Los principios de la universidad se basan en diversos conceptos, como la interdisciplinariedad, la interculturalidad, el bilingüismo y la integración. Según el Plan de Desenvolvimiento Institucional (UNILA, 2013a), la UNILA estimula la integración mediante una amplia cantidad de carreras ofrecidas a profesores $y$ estudiantes de todos los países de América Latina y el Caribe, generando de esa manera un espacio bilingüe. Este bilingüismo es dado oficialmente entre la lengua portuguesa y lengua española, en los ámbitos administrativos, científicos y pedagógicos de la universidad, y es fomentado mediante materias de lenguas adicionales, obligatorias a todas las carreras de la institución. Esta obligatoriedad se da a través de la creación del Ciclo Común de Estudios, quien, además de contemplar la enseñanza de las disciplinas de Portugués/Español como Lenguas Adicionales, presenta también materias como: Fundamentos de América Latina I, II y III con el fin de brindar conocimientos básicos sobre el continente y reforzar los lazos entre los países que lo conforman; 
Evaluación de nivelación y la enseñanza de lenguas adicionales en el contexto UNILA | 185

Introducción al Pensamiento Científico y Ética y Ciencia, disciplinas de aproximación a los conceptos filosóficos occidentales y su relación con el ámbito científico.

El Proyecto Pedagógico del Ciclo Común de Estudios (UNILA, 2013b) afirma, entre otras cosas, que la enseñanza de lenguas adicionales busca desenvolver la comprensión y producción textual en la lengua que se está enseñando, y que, comúnmente, este proceso es dividido en diferentes niveles, donde el estudiante desarrollará diversos conocimientos de la lengua en cuestión. A partir de esto y del contexto institucional de la UNILA, se planteó una estructura de tres niveles para la enseñanza de Portugués y Español como lenguas extranjeras: Básico, Intermediario I e Intermediario II. En el caso del curso de Letras, además de estos tres, son obligatorios los niveles Avanzado I y II.

Durante los niveles básicos, según el Proyecto Pedagógico del Ciclo Común (UNILA, 2013b), se espera que los estudiantes lleguen a obtener el conocimiento necesario de la lengua estudiada, pudiendo interactuar de manera simple, no solo con el medio sino también con sus pares. Estos niveles tienen como objetivo desenvolver las competencias lingüísticas (fonéticas, fonológicas, morfosintácticas, etc.) y la comprensión de textos científicos. Los niveles básicos son cursados durante el primer semestre de cada carrera y poseen, generalmente, una carga horaria de 120 horas, aunque en algunos casos esta carga es de 90 horas.

El Proyecto Pedagógico del Ciclo Común (UNILA, 2013b) afirma que lo largo de los niveles intermediarios, los estudiantes producirán textos escritos y orales más desarrollados, con buena argumentación dentro del entorno académico y sostiene que el objetivo de estos niveles es desenvolver las competencias lingüísticas e interculturales para la interacción en la lengua adicional con mayor grado de complejidad y en contextos menos familiares. Este nivel se divide en dos disciplinas: Intermediario I e Intermediario II. La primera tiene una carga horaria de 120 horas, mientras que la segunda presenta una carga horaria de 60 horas. (UNILA, 2013b)

Los niveles avanzados son, actualmente, materias obligatorias del curso de Letras, donde se espera que los estudiantes obtengan los recursos lingüísticos e interculturales necesarios para participar de interacciones con mayor grado de fluidez y espontaneidad, teniendo a disposición un amplio repertorio lingüístico. (UNILA, 2013b). Durante estos niveles, se pretende, también, que los alumnos puedan perfeccionar las diferentes 
habilidades de producción y comprensión de textos escritos y orales. Las materias de estos niveles son dos: Avanzado I y Avanzado II, y cada una cuenta con una carga horaria de 68 horas.

Es importante mencionar que durante el primer semestre de ingreso, los estudiantes que presenten conocimiento sobre alguna de las lenguas adicionales presentes en la UNILA, pueden optar por realizar una prueba de nivelación (UNILA, 2013b). Estas pruebas se realizan en las modalidades escritas y orales y tienen como objetivo verificar la competencia lingüística del alumno y de esa manera, definir su nivel de conocimiento para incorporarlo a la clase de lengua adicional correspondiente, es decir, que los resultados de la prueba pueden servir para la dispensa de disciplinas específicas de lenguas, presentes en los planes de estudios de todos los cursos. Es fundamental resaltar la consecuencia de este examen, como bien lo menciona McNamara (2008), pues según el resultado de esta evaluación el alumno podrá ser dispensado de hasta 436 horas de clases de la lengua en cuestión.

En este trabajo enfatizaremos en los exámenes de nivelación realizados a alumnos que tengan al portugués como lengua adicional en la UNILA, estudiando cada prueba aplicada desde el año 2014 hasta el 2017. Haremos la descripción detallada de la estructura de estas pruebas a lo largo de nuestro artículo, pero nos encontramos con la necesidad de realizar una breve presentación de éstas a continuación.

Cada prueba de dispensa cuenta con 2 tareas, cada tarea posee textos de lectura y propósitos: textos de producción. Catalogaremos estos textos de lectura y producción según los conceptos de Marcuschi (2008) sobre género textual, dominio discursivo, soporte, etc. , analizaremos el contenido de las pruebas y a partir de este análisis estaremos infiriendo en si los exámenes fueron evolucionando con el paso de los años, qué exigen estas pruebas, qué se considera debe saber el alumno para ser dispensado de las disciplinas de portugués como lengua adicional y cuál es la función de las clases de lenguas en la UNILA.

\section{Marco teórico}

\subsection{Lenguaje y enseñanza de lenguas}

La lengua, según la teoría estructuralista de Saussure, era definida como un conjunto de convenciones necesarias adaptadas por la sociedad, donde el sujeto social es pasivo, es decir que la adquiere y adopta, pero no 
Evaluación de nivelación y la enseñanza de lenguas adicionales en el contexto UNILA | 187

la modifica. Este sujeto adquiere la lengua pero no nace con ella. (COSTA, 2008).

Aunque se ha tomado esta definición por años, a diferencia de Saussure, Mijaíl Bajtin (1895-1975) toma para sus análisis lingüísticos a la lengua en su dinámica, dentro de situaciones sociales inmediatas, en contextos situacionales, donde cada acontecimiento es expresado entre dos personas socialmente organizados dentro de un contexto, al sostener esto, Bajtin se opone al teórico antes mencionado (VOLOSHINOV, BAJTIN 1929)

Torres Vindas (2007) afirma que Bajtín en oposición a las teorías estructuralistas, decide estudiar al lenguaje en su forma dinámica, dentro de prácticas sociales, en contextos y expresados entre personas socialmente contextualizadas. Para él, el lenguaje es el acto concreto del habla, visto como una ida y vuelta comunicativa.

Valentín Voloshinov y Mijaíl Bajtín (1929), expresan que es un acto erróneo afirmar que la lengua es un sistema de normas incuestionables y fijas, que sería más coherente relacionarla a la consciencia individual, o sea, decir que la lengua es inseparable de su contenido ideológico y vital.

Bajtín lanzó las bases para el refinamiento de un concepto de lenguaje como lenguaje actividad social y, al mismo tiempo cognitivo, en que la interacción es co-construida entre sujetos. En ese sentido, el lenguaje se manifiesta en prácticas orales y escritas por medio de las cuales el hombre recorre al sistema lingüístico (léxico, fonología, morfología, etc.) para la construcción de sentido. Esa noción de lenguaje fundamenta el presente trabajo.

En la perspectiva de enseñanza de lenguas adicionales, Dias (2009) sigue la misma teoría de que lenguaje es de naturaleza interaccionista, como una práctica social en situaciones reales y concretas. Esta concepción es demostrada por la autora cuando expresa su visión de enseñanza, diciendo que "El trabajo de manera colaborativa es muy importante en el proceso de enseñanza-aprendizaje” (DIAS, 2009, p. 205). La autora se apoya en la visión socio-interaccionista del lenguaje al establecer criterios de evaluación de libros didácticos para la enseñanza de lenguas adicionales utilizados en diferentes escuelas del país a través del Programa Nacional de Livro Didático (PNLD). Recientemente los libros didácticos fueron incorporados al programa, surgiendo así la necesidad de establecer criterios de evaluación de los materiales presentados por las editoriales para componer o no la lista de oferta de libros que pueden ser 
distribuidos por el Ministerio de Educación a las escuelas públicas brasileras

Dias (2009) enfatiza que es a partir de allí que surge la idea de crear un instrumento con criterios para la evaluación de tan importante recurso pedagógico.

Según la autora, en el caso de la enseñanza-aprendizaje de una lengua extranjera, el hecho de que el aprendiz tenga cierto conocimiento de la estructura de diferentes géneros textuales en su lengua materna, ayuda a la comprensión de éstos escritos en LE. Esto ocurre con los géneros textuales utilizados en la sociedad, en el cotidiano porque pertenecemos a una sociedad letrada, como las propagandas, los e-mails, cartas, noticias, invitaciones, etc. (DIAS, 2009). Como instrumento de esa evaluación, Dias (2009) brinda 6 fichas que incorporan criterios evaluativos relacionados al libro didáctico de lengua extranjera en las que se encuentran temas de análisis como: principios norteadores, composición gráfico-autoral y autonomía; comprensión y producción escrita-oral y aspectos de evaluación relacionados al manual del profesor. Para la elaboración de estas fichas la autora se fundamentó en las directrices norteadoras de los PCN-LE (Brasil: MEC/SEF 1998) y en los documentos del PNLD de Lengua Portuguesa (Brasil: MEC/SEF 2007).

Cabe resaltar que el estudio de los géneros textuales es una de las maneras de estudiar las prácticas de lenguaje materializados en actividades de producción y de recepción de textos. Es allí que Renildes Dias (2009) y Lúcia Cristovao (2007) coinciden, pues ambas consideran que los géneros textuales pueden ser utilizados en la enseñanza de lenguas extranjeras, además de que Cristovao (2007) también se apoya en la teoría sociodiscursiva, o sea, defiende la idea de que el conocimiento es aprendido en actividades colectivas sociales.

Cristovão (2007) se basa en autores como Bronckart, Bajtín, Dolz y Schneuwly -entre otros - y a partir de las teorías de éstos, expresa que el estudio de diferentes géneros textuales en la escuela como instrumento para el proceso de enseñanza-aprendizaje puede generar condiciones para la construcción de conocimientos lingüísticos-discursivos que son fundamentales para las prácticas de lenguaje. Después de esto, la autora presenta varios géneros textuales que cree pueden ayudar en este proceso de enseñanza-aprendizaje de una lengua extranjera, como por ejemplo: historietas, cuentos, noticias, anuncios, artículos de divulgación científica, etc. 
Evaluación de nivelación y la enseñanza de lenguas adicionales en el contexto UNILA $\mid 189$

Marcuschi (2008, p. 155), entiende que género textual "Son los textos que encontramos en nuestra vida diaria y presentan padrones sociocomunicativos [...] formas textuales escritas u orales bastante estables, histórica y socialmente situadas"

Carolyn Miller (1984) citada por Marcuschi (2008, p.159) sostiene que

Los géneros textuales son formas verbales de acción social estabilizadas y recurrentes en comunidades de prácticas en dominios discusivos específicos[...]Resumidamente, se podría decir que los géneros son entidades: a) dinámicas; b) históricas; c) sociales; d) situadas; e) comunicativas; f) orientadas a fines específicos; g) ligadas a determinadas comunidades discursivas; $\mathrm{h}$ ) ligadas a dominios discursivos; i) recurrentes y j) estabilizadas en formatos más o menos claros.

Marcuschi (2008), también habla sobre los diferentes soportes de géneros textuales, diciendo que el género siempre es identificado y se define por su relación con el soporte, es decir que el soporte de un género es una superficie física con un formato especifico que soporta, fija y muestra un texto. Según el autor, el dominio discursivo es una esfera de la vida social o institucional (religiosa, jurídica, militar, familiar, etc.) en la que se dan practicas que organizan formas de comunicación y respectivas estrategias de comprensión y agrega que "De esa manera los dominios discursivos producen modelos de acción comunicativa que se estabilizan y se transmiten de generación en generación con propósitos y efectos definidos y claros" (MARCUSCHI, 2008, p.194).

Marcuschi (2008), intenta realizar una distribución de los géneros orales y escritos según dominio discursivo y modalidad (escrita u oral). Dentro de uno de los tantos dominios discursivos que clasifica, tenemos los siguientes dominios discursivos: instruccional, periodístico, religioso, salud, comercial, industrial, jurídico, publicitario, ocio, interpersonal, militar y ficcional. Algunos de estos serán detallados en nuestro análisis porque tomaremos estos conceptos teóricos como categorías para analizar las tareas de las pruebas estudiadas. 


\subsection{Enseñanza y evaluación de lenguas adicionales}

Tim McNamara, profesor de lingüística y lingüística aplicada en Australia, realizó una conferencia en Argentina en el año 2008. En ésta, McNamara (2008) habla sobre el significado de evaluación, los procesos de evaluación y el acto de evaluar, entre otros. McNamara (2008) afirma que la evaluación, en el contexto de la enseñanza de lenguas, tiene como meta sacar una conclusión acerca de cuánto sabe o qué puede llegar a realizar una persona. El autor explica que alcanzar una conclusión significa comparar a un individuo con otro; a un individuo con un estándar o nivel, y a partir de ello, ver en qué posición está la persona, si por debajo o por encima del nivel estipulado. Se deben seguir algunos pasos a la hora de realizar una evaluación, siendo uno de ellos la recolección de pruebas, lo cual se realiza mediante el examen, por eso que el profesor hace énfasis en que se debe decidir de manera muy consciente lo que se pide al alumno y pensar de qué forma eso ayudaría a sacar una conclusión sobre la situación del estudiante, sobre qué saben o qué pueden hacer, y sólo a partir de esa conclusión, se toma la decisión: ¿qué se va a enseñar a continuación?, ¿se deja que el alumno pase al siguiente nivel?, etc.

Según McNamara (2008) es importante tener en cuenta teorías de medición a la hora de corregir exámenes de importantes consecuencias en la vida de las personas que lo realizan, como por ejemplo, exámenes de ingreso a la universidad, para la obtención de ciertos puestos de trabajo, y por qué no un examen como el que se realiza en el CELPE-BRÁS, teniendo en cuenta la importancia de éste al ser el único certificado de competencia en portugués para extranjeros reconocido por el Estado brasileño, siendo necesario para el ingreso a universidades y puestos de trabajo en el país.

El examen Celpe-Bras es una prueba de proficiencia lingüística y mediante ésta, el participante es certificado sobre su habilidad de uso de la lengua portuguesa en las modalidades escrita y oral. Se trata de un examen a gran escala aplicado en diversos lugares del mundo, inclusive en la UNILA. La prueba de nivelación, a su vez, tiene como propósito principal evaluar la posibilidad de dispensar a los estudiantes de una o más disciplinas obligatorias ofrecidas en el contexto del ciclo común de la UNILA. En ese sentido, la prueba de nivelación/dispensa que analizaremos en este trabajo está directamente relacionada a las directrices 
Evaluación de nivelación y la enseñanza de lenguas adicionales en el contexto UNILA | 191

de la enseñanza-aprendizaje de lengua portuguesa adicional para los alumnos de la UNILA.

Siendo foco de su análisis la prueba Celpe-Bras, Matilde Scaramucci (1995) trata cuestiones relacionadas a la implementación de este examen en el contexto del Mercosur que están ligadas a la naturaleza del examen, como la base comunicativa y la definición de proficiencia, entre otras cosas. Scaramucci (1995) explica que para obtener un abordaje comunicativo en este examen, la Comisión Organizadora optó por el uso de un sistema que sea utilizado en situaciones reales comunicación. A partir de esa visión, un usuario competente de la Lengua Extranjera debería saber usar la lengua en diversos contextos, adecuados a las situaciones socioculturales y a sus interlocutores. Según la autora, este abordaje comunicativo se concretó en las pruebas de CELPE-BRÁS Certificado de competencia en Lengua Portuguesa para Extranjeros mediante el uso de diferentes actividades llamadas "tareas", lo que podemos relacionar con las pruebas de nivelación aplicadas en la UNILA, pues también se utilizan tareas para crear ese abordaje comunicativo.

Scaramucci (1995), afirma que el término "tarea" se refiere a una actividad de enseñanza o de evaluación: “[...] tiene un propósito comunicativo, y busca especificar para el lenguaje, usos que se asemejan o son cercanos de aquellos que tienen en la vida real" (SCARAMUCCI, 1995, p.80) La autora afirma también, que la tarea admite la presentación de contenidos auténticos, o sea, se pueden utilizar textos extraídos de diarios, libros, revistas, etc. que no son elaborados para justamente la enseñanza de una lengua. La tarea sería una manera de simular prácticas sociales de lenguaje con el objetivo de enseñar o de evaluar. En la elaboración de la tarea, se consideran diversos géneros textuales para la lectura y, al proponer una simulación del lenguaje teniendo como parámetro las situaciones reales de uso del lenguaje, en la consigna de la tarea se busca definir los papeles de la interacción entre los participantes, la complejidad o no del lenguaje, entre otras cuestiones que analizaremos en las tareas de las pruebas de nivelación a continuación.

De acuerdo con Scaramucci (1995) el uso de tareas en un examen tiene varias ventajas, como por ejemplo: el mostrar situaciones que son semejantes a las situaciones reales de comunicación, muestran con claridad lo que está siendo evaluado y a su vez, es más motivador para los candidatos, pero la autora afirma que posiblemente la mayor ventaja de esto sería la presentación de un propósito u objetivo claro, que establece el contexto y los límites de la evaluación. La autora cita a Urquhart (1987, 
apud SCARAMUCCI, 2008, p.81-82) diciendo "Una situación comunicativa envuelve a un hablante (autor del texto), el mensaje (texto), un interlocutor (lector) y también un propósito".

Una vez discutidos los principales conceptos teóricos que fundamentan este trabajo, a continuación pasamos hacia nuestro análisis.

\section{Análisis y descripción de las tareas de las pruebas de nivelación}

Las pruebas de nivelación - realizadas en la Universidad Federal de Integración Latinoamericana - denominadas también pruebas de dispensa, consisten en eximir al estudiante de las clases de Portugués como Lengua Adicional, ministradas en la misma universidad. Esta dispensa es efectuada mediante diferentes niveles según la nota alcanzada por el alumno, es decir que si el alumno obtiene la nota exigida para el nivel básico, será eximido de esa materia y así sucesivamente con las demás disciplinas de lengua extranjera.

Estas pruebas se han aplicado desde el año 2014 hasta la actualidad, pero para nuestro análisis tomaremos las pruebas que se llevaron a cabo desde el año 2014 hasta el 2017. En ese lapso de tiempo, se realizaron 5 ediciones, es decir, han sido 5 exámenes: 2014.1; 2015.1; 2016.1; 2017.1 y 2017.2. Cada prueba presenta dos tareas: Tarea 1 y Tarea 2. Cada una de ellas cuenta, generalmente, con un texto de lectura en lengua portuguesa, el cual ha variado durante las diferentes ediciones respecto a género, tema, soporte y extensión. De la misma manera, los textos a ser desarrollados por los alumnos también fueron cambiando durante las diversas ediciones. El total de las tareas que analizaremos es de 10 , puesto que son 5 pruebas y cada prueba cuenta con 2 tareas.

Como hemos mencionado anteriormente, cada prueba cuenta con 2 tareas, donde se supone que cada tarea cuenta con su nivel de complejidad. Es probable que la tarea numero 1 sea más sencilla, presentando un texto de lectura y un trabajo de redacción simples; y la tarea numero 2 quizás presente un texto de lectura y un texto de redacción un poco más complejo en comparación con la tarea numero 1.

Para poder llegar a esta conclusión y realizar la descripción y análisis de las tareas, primero tomaremos los textos de lectura de cada edición con sus respectivos géneros textuales, año de publicación, fuente, soporte, dominio discursivo y la cantidad de palabras que poseen para poder conocer la dimensión de los textos; luego citaremos la consigna y seguido, el texto de producción donde catalogaremos su género textual y 
Evaluación de nivelación y la enseñanza de lenguas adicionales en el contexto UNILA | 193

dominio discursivo; y para finalizar la descripción de cada edición haremos comentarios sobre los textos de lectura y los textos de producción. Siendo breves, la descripción será de la siguiente manera: $1^{\circ}$, texto de lectura utilizado: fuente, número de palabras, soporte, dominio discursivo y genero textual. $2^{\circ}$ - consigna y texto de producción solicitado: propósito, género textual y dominio discursivo. $3^{\circ}$ - comentarios sobre texto de lectura y texto de producción: análisis y comparación entre los textos de lectura y producción, comparación entre las tareas de una misma prueba y también con tareas de otras ediciones.

Para realizar nuestro análisis e identificar los textos de lectura y de producción, utilizamos algunos conceptos y definiciones, como el de género textual, dominio discursivo y soporte. Sobre género textual, nos basamos en la definición realizada por Marcuschi (2008, p. 155): "Son los textos que encontramos en nuestra vida diaria y presentan padrones socio-comunicativos [...] formas textuales escritas u orales bastante estables, histórica y socialmente situadas". Para definir soporte, Marcuschi (2008) afirma que los soportes de géneros textuales son una superficie física con un formato específico que soporta, fija y muestra un género textual. Describimos algunas características de los soportes que notamos aparecieron con más frecuencia en las pruebas de nivelación según nuestro análisis:

El diario es un soporte con muchos géneros. Estos géneros, en buena medida, típicos y reciben, en función del soporte, algunas características en ciertos casos, tal como el de la noticia. Aquí también se sitúan las cartas de lectores y las notas sociales, entre otros. En el diario, tenemos géneros que no aparecen en revistas semanales, como: anuncios fúnebres, previsiones meteorológicas, horóscopos [...] pero hay otros comunes con las revistas como noticias, editoriales, recetas culinarias, entrevistas, historietas, etc. (p.179-180)

Otro soporte que nos resulta importante mencionar, es la revista científica, ya que en nuestro análisis encontramos que este tipo de soporte fue utilizado reiteradas veces, y Marcuschi (2008) lo define como:

[...] soportes de géneros bastante específicos y ligados a un dominio discursivo (el científico, académico o 
instruccional). Allí encontramos artículos científicos [...] y otros de esa naturaleza [...] Por el hecho de ser considerados científicos, hay inclusive un status de los géneros por ellos vehiculados que es diferente de los textos similares que aparecen en diarios o revistas semanales [...] (p. 180)

Continuando con los conceptos utilizados para el análisis, Marcuschi (2008) afirma que el dominio discursivo es una esfera de la vida social o institucional (religiosa, jurídica, militar, familiar, etc.) en la que se dan prácticas que organizan formas de comunicación y respectivas estrategias de comprensión. El autor, además, intenta agrupar géneros orales y escritos según su dominio discursivo y modalidad. Para nuestro análisis utilizaremos la concepción de los dominios discursivos: instruccional, periodístico, jurídico, interpersonal y ficcional, porque fueron estos los dominios que encontramos presentes en las pruebas de nivelación estudiadas.

El primer género que mencionamos, según Marcuschi (2008) es el género discursivo con más circulación en el ámbito académico, pues incluye todo lo que tenga relación con lo científico, académico y educacional. Por ejemplo, en la modalidad escrita están los artículos científicos, artículos de divulgación científica, resúmenes de libros, carta de recomendación, entre otras; en lo que se refiere a la modalidad oral: están las conferencias, debates, exámenes orales, aulas en video, etc. Marcuschi (2008) afirma que dentro del género discursivo periodístico se encuentran las noticias, los reportajes, artículos de opinión, comentarios, historietas, tiras humorísticas, etc. El autor indica que en el género jurídico podemos ubicar a los contratos, leyes, reglamentos, certificados, entre otros. Los e-mails, formularios, cartas de lectores, cartas personales, listas de compras, etc. Se localizan en el género interpersonal y por último, el género ficcional: cuentos, poemas, novelas, crónicas, etc. (MARCUSCHI, 2008).

Entendidos estos conceptos, podemos empezar con el análisis y descripción de las pruebas con sus respectivas tareas. 


\subsection{Edición 2014.1}

\section{Tarea número 1}

Este fue el año en que se aplicó por primera vez la prueba de dispensa en la UNILA, siendo también la única edición realizada durante el año.

El examen realizado durante el año 2014 presentó un texto de lectura llamado "Estudantes do mundo embarcam na Ruta Inka", publicado en el año 2010, en el diario digital "Carta Capital".

El texto, perteneciente al dominio discursivo periodístico, del género noticia, contó con la extensión de 227 palabras. Este texto informaba a la comunidad estudiantil sobre el inicio de las inscripciones para un viaje-aventura hacia diversas comunidades indígenas. El objetivo de del viaje era formar jóvenes embajadas de las culturas indígenas de cada región visitada. Esta noticia incentivaba a los alumnos de espíritu aventurero y con interés por los pueblos indígenas a realizar su inscripción y para esa inscripción, debían redactar y enviar en e-mail con una carta de presentación y motivación, recomendación de su centro de estudios y un ensay monográfico.

La consigna de la tarea fue:

"Interessado em participar das viagens da Ruta Inka, envie uma carta de apresentação e de motivação para a Associação, relatando seu conhecimento sobre a região, o que você espera do projeto e como você pode contribuir com ela."

Observamos que la consigna de la tarea solicitó a los alumnos tomar posición como estudiantes interesados en el viaje a la Ruta Inka y de esa manera, cumplir con algunos requisitos mencionados en el texto de lectura. Podemos decir que el texto de lectura parece haber sido de fácil comprensión e interpretación para los estudiantes hispanohablantes aprendices de portugués, pues como menciona Dias (2009): es probable que el alumno tenga cierto conocimiento sobre el género textual noticia en su lengua materna, lo que facilita su comprensión en la lengua adicional.

En cuanto al texto de producción, se pidió a los alumnos redactar una carta de presentación, lo que según Marcuschi (2008) pertenece al dominio discursivo instruccional. 


\section{Tarea número 2}

En la tarea numero 2 de la prueba del año 2014, el texto de lectura se llamó "É fogo" del poeta y escritor Fernando Brant, publicado en el diario digital "Diario Impresso". Este texto de dominio discursivo ficcional, pertenece al género textual crónica y tiene 468 palabras donde el autor relata la importancia del fuego en la historia de la humanidad y en el uso cotidiano actual. A manera de crítica, el autor expresa el lado negativo del fuego durante las manifestaciones y reclamos del pueblo, pues para Brant la quema de objetos en las marchas sociales es de poca ayuda y recomienda utilizar las llamas en algo más producente. A partir de esta opinión, el autor invita a los lectores a la reflexión sobre el uso de los métodos que involucran el uso del fuego para lograr buscar una alternativa que pueda ser más productiva para la sociedad.

Presentamos a continuación la consigna de la tarea:

"Apresente a idéia central desenvolvida por Fernando Brant na crônica "É fogo" e emita sua própria opinião em relação a ela."

En esta situación, una crónica es un relato que narra hechos de nuestro cotidiano y puede resultar más difícil de interpretar que una noticia, género textual que se utilizó en el texto de lectura de la tarea anterior. Podemos argumentar esto con la afirmación de Dias (2009) quien sostiene que los géneros textuales que circulan en nuestro cotidiano, una noticia por ejemplo, probablemente sean de fácil comprensión, mientras que el género crónica puede que no circule con tanta frecuencia en el día a día de una sociedad.

Sobre el texto de producción afirmamos que no tuvo un género textual definido, pues el alumno debía presentar ideas principales y omitir una opinión. En este caso, nos basamos en Marcuschi (2008) para catalogarlo dentro del dominio discursivo periodístico, ya que se solicitó emitir una opinión sobre un tema, lo que podría compararse con un artículo de opinión.

Después de haber descrito ambas tareas, podemos decir que probablemente la tarea número 2 exigió mayor capacidad de comprensión y de redacción que la tarea numero 1 . Partiendo de la base que le genero noticia podría resultar familiar para el alumno, lo cual ayuda en la comprensión y el género crónica al ser un genero poco común en nuestro cotidiano podría presentar un trabajo de comprensión un poco más 
Evaluación de nivelación y la enseñanza de lenguas adicionales en el contexto UNILA | 197

complejo. Lo mismo sucede con los textos de producción: el texto de producción de la tarea número 1 fue una carta de presentación y como el mismo género lo dice, el alumno debía básicamente presentarse, pero en texto de producción de la tarea número 2 se solicitó a los estudiantes realizar una crítica, lo que exige al alumno comprender el texto de lectura en su totalidad para luego poder tomar una posición sobre el tema y emitir su opinión. En síntesis, es posible que la tarea número 2 haya sido más compleja que la tarea número 1 del examen de dispensa del año 2014.

\subsection{Edición 2015.1}

\section{Tarea número 1}

La tarea número 1 tuvo como texto de lectura el reglamento de la biblioteca de la UNILA y según Marcuschi (2008) todo reglamento pertenece al dominio discursivo jurídico.

Este reglamento cuenta con 1518 palabras donde presenta asuntos del cotidiano académico y que posiblemente sean de utilidad para la comunidad estudiantil.

La consigna de esta tarea fue:

"A partir da leitura do Regulamento da Biblioteca Paulo Freire-PTI, escreva um e-mail para seu amigo, estudante da UNILA, que se esqueceu de devolver um livro no prazo. No seu e-mail, você deve informá-lo como regularizar a situação junto a biblioteca e sobre as conseqüencias de não devolver o livro no prazo."

Haciendo observaciones hacia el texto de lectura, podemos decir que el reglamento, a pesar de ser extenso - 1518 palabras - puede que haya sido de fácil comprensión para los alumnos, porque tal vez los Estudiantes ya estén acostumbrados a este género textual, pues es usual leer reglamentos a lo largo de nuestras vidas y aún con más frecuencia en el ámbito universitario.

Sobre el texto de producción, se solicitó los estudiantes redactar un e-mail y Marcuschi (2008) lo considera de dominio discursivo interpersonal. El hecho que sea un e-mail a un amigo, una escrita personal e informal, puede haber sido un trabajo simple, además de que el alumno ya conoce sobre este género textual en su lengua materna. 


\section{Tarea número 2}

El texto utilizado en esta tarea fue "Fraude automática: Textos gerados por computadores enganam publicacoes academicas mesmo quando desprovidos de sentido". Perteneciendo al dominio discursivo instruccional, del género textual articulo de divulgación científica del autor Edgard Murano, publicado en "Revista Portuguesa" en el año 2014. Este artículo de divulgación científica cuenta con 1045 palabras, donde el autor relata que no todos los textos publicados en revistar científicas son precisamente escritos por investigadores, pues existen una gran cantidad de textos escritos por robots y están siendo publicados en periódicos académicos. Según Murano, esto nos debe llevar a estar más atentos a la credibilidad de la información que adquirimos para nuestras investigaciones.

Siendo la consigna de la tarea:

"Você participa de um grupo de pesquisa que tem um fórum de discussão. A partir da leitura do artigo Fraude Automática, escreva um comentário para seus colegas de grupo, discutindo a questão abordada no artigo e suas conseqüências para a seleção de textos."

El texto de Edgar Murano, además de ser un texto extenso, el tema que presentó era complejo porque exigía del estudiante el conocimiento de cómo funciona la publicación y circulación de textos académicos en revistas especializadas y también, sobre las cuestiones relacionadas a los debates sobre plagio y autoría, lo cual podría influir en la comprensión texto. Al ser un artículo de divulgación científica posee información especifica que no circula entre un público general, es por ello que tal vez muchos alumnos aprendices de portugués como lengua adicional hayan tenido problemas de comprensión pues probablemente no circulen textos de éste género textual en lengua materna en su cotidianidad.

En cuanto al texto de producción, el estudiante debía escribir un comentario y Marcuschi (2008) lo clasifica dentro del dominio discursivo instruccional. Podemos resaltar que a pesar de que realizar un comentario tal vez no sea tan complicado, el hecho de que el texto de lectura sea complejo torna a la redacción del comentario un trabajo difícil. Es decir que la mayor dificultad se encuentra en el texto de lectura lo que también se refleja en el texto de producción. 


\subsection{Edición 2016.1}

\section{Tarea número 1}

En este año, la prueba de nivelación presentó algo novedoso: dos textos de lectura utilizados para una misma tarea. El texto número 1 fue un texto escrito y texto número 2 fue una imagen.

El texto número 1 (texto escrito) fue del género reportaje, titulado "A relatora da ONU para direitos indígenas veio ao Brasil e se opos a mudar a regra de demarcacao de terras" y ha sido publicado en el diario online "Nexo Jornal”.

El dominio discursivo de dicho texto es el periodístico, donde se relata que una integrante de la ONU, encargada de los derechos de los pueblos originarios no aceptó la propuesta que cambiaría la ley vigente sobre las reservas de tierras destinadas a indígenas, pues para ella esta propuesta legislativa reduce la chance de que los nativos obtengan su derecho a las tierras.

Como texto número 2 se utilizó la imagen "Ferramentas de demarcacao de terras" creada por el caricaturista brasileño Carlos Latuff.

La imagen presenta tres de los grandes sectores sociales: el gobierno, los indígenas y los campesinos, donde cada uno presenta su método de defensa o ataque ante las demarcaciones de tierras: el gobierno con bolígrafo en mano, los indígenas con arco y flecha, y los campesinos con arma de fuego.

Una vez leído e interpretado ambos textos, la consigna fue la siguiente:

"Você é estudante da disciplina de Fundamentos de América Latina (FAL) e está trabalhando em aula com o tema de demarcação de terras para as comunidades indígenas no Brasil. Como atividade da disciplina, elabore um artigo de opinião (entre 20 a 30 linhas), contendo: O contexto social da reportagem; Possiveis relações entre os dois textos; Posicionamento crítico sobre o assunto".

Como ya hemos mencionado antes, esta edición (2016) fue la primera en utilizar dos textos de lectura para una misma tarea, al mismo tiempo, es la primera que pide a los alumnos relacionar dos textos para elaborar una actividad. Aunque leer e interpretar un reportaje puede resultar sencillo, por la familiaridad del alumno con el género textual en su lengua materna, el hecho de tener que relacionarlo con otro texto, tal vez haya sido dificultoso. 
Sobre el texto de producción, se solicitó a redactar un artículo de opinión, o sea, de dominio discursivo periodístico. No queríamos dejar pasar por alto otra novedad presente en esta prueba, ésta vez en la consigna de la tarea: se planteó explícitamente lo que el texto de producción debía contener, de la siguiente manera: contener el contexto social del reportaje; posible relaciones entre los dos textos; posicionamiento crítico y poseer entre 20-30 líneas.

Esta exigencia podría ser de ayuda para los alumnos o todo lo contrario, ya que para cumplir con todo lo que se pidió, el estudiante tenía que haber comprendido perfectamente ambos textos, pero quienes no lo lograron, tendrían dificultades y entonces estas normas a seguir serían un obstáculo.

\section{Tarea número 2}

En la tarea número 2 del año 2016 se utilizó un texto del género textual reportaje bajo el título de "Por pressao, planos de educacao de 8 Estados do Brasil excluem a ideología de género" de los autores Patricia Britto y Lucas Reis.

Este reportaje de 982 palabras, correspondiente al dominio discursivo periodístico, relata que diputados de por lo menos Estados brasileños suprimieron de los planes de educación temas referidos a la identidad de género, diversidad y orientación sexual. Los autores expresan que quienes defienden esta decisión se basan en discursos hechos por la iglesia, pero a pesar de que muchos defienden esta idea, están también quienes se oponen, argumentando que las escuelas necesitan estar preparadas para combatir la discriminación de género y tener conocimientos básicos sobre la sexualidad.

La consigna fue:

"Você participa de um grupo de pesquisa que estuda a relação entre educação e políticas de gênero no Brasil. Por meio da reportagem publicada no site do jornal Folha de São Paulo, elabore um comentário (entre 15 a 20 linhas) a ser publicado no fórum permanente de discussão de seu grupo. Em seu texto, você deve: Fazer uma breve apresentação do assunto tratado na reportagem; A partir das informações presentes no texto, defender uma posição pessoal acerca do assunto." 
Evaluación de nivelación y la enseñanza de lenguas adicionales en el contexto UNILA | 201

En esta actividad también se repite la misma situación que en la tarea anterior, la consigna presenta a manera de guía lo que el texto de producción debía contener: hacer una breve presentación del asunto tratado en el reportaje; a partir de las informaciones presentes en el texto defender una posición personal sobre el asunto y poseer entre 15-20 líneas. Como ya hemos dicho, esto puede ayudar o no al alumno.

El texto a ser producido por los alumnos fue un comentario, siendo su dominio discursivo el instruccional.

Realizando una comparación entre las dos tareas de este examen, podemos expresar que posiblemente la tarea número 1 haya sido más compleja: presentado 2 textos de lectura y además tiene como texto de producción un artículo de opinión, un género textual que el alumno quizás no esté acostumbrado a tratar y elaborar.

\subsection{Edición 2017}

A diferencia de los años anteriores, la prueba de nivelación aplicada en la UNILA, se realizó 2 veces: 2017.1 durante el primer semestre y 2017.2 en el segundo semestre.

\subsubsection{Edición 2017.1}

La tarea número 1 del 2017.1 presentó como texto de lectura el trecho de un ensayo académico del autor Rajagopalan, titulado "Lingua estrangeira e autoestima" conteniendo 958 palabras. Este ensayo, de dominio discursivo instruccional, fue publicado en el libro Parábola, en el año 2003.

Rajagopalan en su texto expresa que actualmente quien domina una lengua extranjera es admirado y denominado persona culta y diferente, tal es así que la palabra "extranjera" es utilizada para calificar una lengua que cuenta con más prestigio que la propia lengua materna. El autor, además, afirma que existió la premisa de que ningún hablante no nativo jamás puede soñar con adquirir un dominio perfecto del idioma. Esta premisa lleva a que muchos estudiantes se sientan avergonzados de su condición lingüística, lo que genera un complejo de inferioridad y disminuye sus autoestimas. Rajagopalan sostiene que a pesar de que eso aún siga ocurriendo, actualmente la realidad lingüística es otra, pues las lenguas mixtas como el "portuñol" o el "spanglish" son cada vez más utilizados. 
La consigna de la tarea fue la siguiente:

"Em umas das disciplinas de Português Adicional na UNILA, você foi convocado à tarefa de escrever um resumo do texto "Lingua Estrangeira e Autoestima" (Rajagopalan, 2003). Em seu texto, você deverá apresentar idéias centrais e periféricas defendidas pelo autor sobre o processo de ensino-aprendizagem de uma lingua estrangeira."

El texto de lectura, pese a que fue un ensayo académico presentó un lenguaje de fácil comprensión y un tema que podría resultar interesante para los alumnos, pues trata de la realidad de quien está aprendiendo una lengua adicional.

En cuanto al texto de producción, éste fue del dominio discursivo instruccional ya que el género textual fue un resumen.

Podemos notar que esta tarea tuvo como texto de lectura y texto de producción géneros textuales volcados al dominio discursivo instruccional, es decir que ambos textos están estrechamente ligados al ámbito académico, lo cual probablemente se asemeja a la realidad que viven los estudiantes en la universidad.

Como el examen del año anterior (2016) esta prueba también plantea de manera explícita lo que el texto de producción debe contener: presentar las ideas centrales y periféricas defendidas por el autor sobre el proceso de enseñanza-aprendizaje de una lengua extranjera.

\section{Tarea número 2}

En la tarea número 2 del año 2017.1, se utilizaron 2 textos de lectura, al igual que en el año 2016, con la única diferencia de que ésta prueba tuvo 2 textos escritos: Texto número 1 y Texto número 2 .

El texto número 1 "Lingua estrangeira e autoestima" también utilizado en la tarea número 1 de este examen y el texto número 2 "Plurilinguismo no Brasil: repressao e resistencia linguistica", el cual es un trecho de un artículo de divulgación científica, con 1116 palabras, del autor brasileño Gilvan de Oliveira, escrito en el año 2009 y publicado en la revista académica Synergies Brésil.

En este articulo de divulgación científica, de dominio discursivo instruccional, el autor asegura que el Estado de Brasil se opone al plurilinguismo, planteando una política que excluye aproximadamente 215 lenguas brasileras de las instituciones de enseñanza. Gilvan expresa 
Evaluación de nivelación y la enseñanza de lenguas adicionales en el contexto UNILA | 203

que se tiene el concepto - o preconcepto - de que ser brasileño es hablar portugués (de Brasil). Aunque históricamente Brasil sea un país plurilingüe, no son reconocidas las demás lenguas, lo que genera un total desconocimiento de diferentes culturas, incentivando cada vez más al prejuicio.

A partir de la lectura de ambos textos, la consigna fue la siguiente:

"Como aluno de uma das disciplinas de Português Adicional Intermediário na UNILA, você foi solicitado a escrever uma resenha critica, articulando as idéias e/ou informações apresentadas nos textos "Língua Estrangeira e Autoestima" (Rajagopalan, 2003) e "Plurilinguismo no Brasil: Repressão e resistência linguística” (Oliveira, 2009). Em seu texto, você deverá:

a) Refletir sobre como a "politica de monolinguismo" presente no contexto brasileiro (apresentada pelo autor do texto 2) afetaria "o processo de "ensinoaprendizagem" de uma lingua "estrangeira" como parte integrante de um amplo processo de redefinição de identidades" (tal como defendido pelo autor do texto 1)

b) Avaliar de que modo o aparecimento de "novos bilinguismos" (conforme afirma o autor do texto 2) pode trazer impactos ao processo de ensinoaprendizagem de uma lingua estrangeira (texto 1), mencionado no item A)"

Resaltamos que hasta ésta edición (2017.1), ninguna prueba había solicitado a los alumnos establecer una relación entre dos textos escritos, recordemos que en el año 2016 los alumnos relacionaron un texto escrito y una imagen. Continuando con las comparaciones, en los exámenes de dispensa aplicados hasta la edición 2017.1, fueron utilizados textos de lectura que presentaban temas generales y frecuentes en el cotidiano de todas las personas, por ejemplo: en el año 2014 se utilizó una noticia; en el año 2015 un reglamento y en el año 2016 ambos textos fueron reportajes. Pero en la edición 2017.1 los dos textos de lectura trataron discusiones polémicas que escapan a nuestro cotidiano, con temas enfocados a un público académico, como un ensayo y un artículo de divulgación científica.

Lo mismo ocurrió con los textos a ser producidos por los alumnos: desde 2014 hasta 2017.1 la mayoría de los textos de producción fueron géneros textuales que frecuentemente circulan en la cotidianidad de una sociedad letrada, como en la evaluación del año 2014 que en la primer tarea el alumno debía redactar una carta; en el año 2015 se pidió escribir un e-mail a un amigo y en la tarea número 2 debía realizar un comentario; 
en el año 2016 el alumno redactó un comentario. En la edición 2017.1 los textos a ser elaborados por los alumnos fueron un resumen y una reseña, géneros relacionados al ámbito académico, siendo ambos de dominio discursivo. Tal vez este examen marcó un antes y un después en las pruebas de nivelamento.

\subsubsection{Edición 2017.2 \\ Tarea número 1}

En el segundo semestre del año 2017, la tarea número 1 presentó como texto de lectura un trecho del articulo de divulgación científica "O valor economico do tempo livre", publicado en la Revista Piseagrama por el autor Ladislao Dowbor, en el año 2011El texto de dominio discursivo instruccional, posee 3115 palabras y trata sobre el tiempo como un nuevo recurso no renovable. El autor afirma que el tiempo es dinero, que el tiempo es tiempo de nuestra valiosa vida y que aunque el dinero perdido puede ser recuperado pero el tiempo que derrochamos no volverá. Dowbor detalla todas las situaciones cotidianas en las que solemos perder muchas horas y les agrega un valor económico, con el fin de hacernos reflexionar sobre diversos problemas que existen en nuestra sociedad y que están relacionados a la regulación y uso del tiempo.

La consigna de esta tarea fue:

"Na disciplina de Português Adicional Básico da UNILA, você foi solicitado a ler "O valor econômico do tempo livre", de Ladislau Dowbor, e escrever um resumo apresentando e relacionando as idéias principais e periféricas do texto. Em um resumo você deve fazer menção à autoria das idéias do texto resumido e escrever com suas palavras as idéias do texto. Citações são permitidas, mas não serão aceitas cópias expressas de trechos dos textos-base."

El texto que se utilizó en esta tarea además de ser un texto extenso, puede que haya sido de difícil comprensión al tratarse de un género con el cual no estamos en contacto en nuestro día a día, por tratar un tema muy específico y poco habitual puesto que el texto está volcado al área de economía.

Nos resulta importante resaltar la extensión del texto: 3115 palabras y sin poder evitar realizar una comparación con uno de los textos utilizados en el año 2014, que presentó la extensión de 227 palabras. El hecho de que el texto "O valor económico do tempo livre" sea extenso, 
Evaluación de nivelación y la enseñanza de lenguas adicionales en el contexto UNILA | 205

sumado a la complejidad del mismo, hacen que probablemente este texto haya sido bastante difícil de ser comprendido, lo cual arrastra la dificultad al texto de producción y sobre el texto de producción podemos decir que fue de dominio discursivo instruccional, del género textual resumen.

\section{Tarea número 2}

La tarea número 2 tuvo 3 textos de lectura, siendo el número 1 el que se utilizó en la primer tarea: "O valor económico do tempo livre" y los otros dos fueron denominados $2 \mathrm{~A}$ y $2 \mathrm{~B}$.

El texto 2A, trecho del ensayo "Dinheiro para um novo mundo" escrito por Belgin y Lietaer, y publicado en la revista de divulgación científica Piseagrama en el año 2017.

Este texto está dentro del dominio discursivo instruccional y cuenta con 209 palabras, en las que los autores narran sobre el surgimiento de los bancos de tiempo y lo benéficos que son para la sociedad.

El texto 2B, trecho de un reportaje llamado "E os bancos de tempo chegaram ao Brasil" de Ana Claudia Araujo, publicado en el diario "Outras Palavras" en el año 2017.

Este reportaje pertenece al dominio discursivo periodístico y en él, la autora explica qué son los bancos de tiempo y cómo funcionan en Brasil.

Siendo la consigna:

"Você faz parte de um grupo de estudantes e professores que está propondo a criação de um banco de tempo para a comunidade acadêmica da UNILA, como o Banco de Tempo (Time Dollars) apresentado nos Textos 2A e 2B. Você foi convocado a escrever o texto de divulgação da proposta a ser divulgado na comunidade universitária. Após ler o Texto 1 (O valor econômico do tempo livre"), e os textos 2A e 2B ("Dinheiro para o mundo novo" e "Os Bancos de tempo chegaram ao Brasil"), escreva um texto intitulado "Por que é importante crias um banco de tempo na UNILA?".

No seu texto, você deve retomar a discussão feita no texto 1 e relacionar com as idéias apresentadas nos Textos 2A e 2B para fundamentar ou embasar com os argumentos dos autores dos textos - base a avaliação da importância de se criar um banco de tempo no contexto da comunidade acadêmica da UNILA. Lembre-se de que você deve fazer menção a autoria das idéias, se for retiradas do 
texto-base. Citações são permitidas, mas não serão aceitas cópias expressa de trechos dos textos-base."

Esta tarea utilizó 3 textos de lectura, con géneros textuales y temas poco usuales en nuestro día a día. Con eso podemos decir que probablemente esta tarea resultó bastante difícil para los estudiantes. A pesar de que los textos $2 \mathrm{~A}$ y $2 \mathrm{~B}$ no fueron demasiado complejos, es posible que el texto número 1-“O valor económico do tempo livre”- sí lo haya sido, como mencionamos en la descripción de dicho texto, es decir, en la parte descriptiva de la tarea número 1 .

Sobre el texto de producción: Marcuschi (2008) lo considera de dominio discursivo publicitario, pues al ser un texto de divulgación, en este caso cumple la función de propaganda o publicidad, ya que debe convencer a la comunidad académica a acceder a la idea de la creación de un banco de tiempo en la universidad.

\section{Consideraciones finales}

Este trabajo tuvo como objetivo presentar y analizar las pruebas de nivelación que se realizan en la UNILA, con el fin de comprender de qué se trata ésta y qué deben saber los estudiantes para ser dispensados de las clases de lenguas adicionales obligatorias en dicha universidad. El análisis se realizó mediante el uso de los conceptos otorgados por Marcuschi (2008) sobre soporte, género textual y dominio discursivo, ya que cada prueba presentaba tareas, en las cuales existía un texto de lectura y una consigna que exigía un texto de producción.

Consideramos que, posiblemente con el pasar de los años, la prueba se haya tornado más exigente, pues los textos de lectura utilizados en el último año (2017) fueron más extensos y complejos, pues presentaron temas que generalmente no son debatidos en los medios de comunicación, que forman parte de la comunidad científica y con géneros textuales más cercanos a los géneros que circulan en el medio académico, como ensayos, trechos de artículos de divulgación científica o artículos académicos. Como mencionamos en nuestro análisis, basamos esta complejidad en que a pesar de que somos una sociedad letrada, hay géneros textuales que no circulan con frecuencia en nuestra vida cotidiana y que por ello, es probable que los desconozcamos en nuestra lengua materna. (DIAS, 2009). 
Evaluación de nivelación y la enseñanza de lenguas adicionales en el contexto UNILA | 207

Los primeros exámenes presentaban géneros textuales que poseían temas más bien generales, que la mayor parte de la sociedad tiene acceso, como noticias, reportajes, reglamento, entre otros. Durante el año 2017 se utilizaron textos académicos, con temas específicos y es en esta parte donde podemos ponernos a reflexionar sobre cuál es el papel de la universidad, qué se espera que el alumno aprenda en una clase de lengua adicional. Si pretendemos que en la universidad aprendan a leer y a comprender noticias, o si debemos orientarlos/encaminarlos hacia lo que enfrentará a lo largo de su vida académica, en las materias especificas de su carrera, recordando que los alumnos extranjeros que pertenecen a la UNILA, tienen la mayoría de clases en lengua portuguesa, porque la mayor parte del cuerpo docente es brasilero. Generalmente los materiales de estudio y trabajos escritos académicos, también son exigidos en lengua portuguesa.

Por la importancia del uso de la lengua portuguesa en la UNILA, cuestionamos que utilizar un género textual del cotidiano y de fácil comprensión en las clases de Portugués como Lengua Adicional es una cosa, pero colocar el mismo género en una prueba que podría dispensar al alumno de hasta 436 horas de clases de la lengua en cuestión, es otra, porque se convierte en un criterio de dispensa y es necesario pensar hasta qué punto es este un criterio coherente con las prácticas de lectura y escritura en lengua portuguesa y materna de los alumnos a lo largo de sus carreras.

Esta situación también se ve reflejada en los textos a ser producidos por los alumnos que realizan el examen de nivelación: en las últimas ediciones se pidieron textos donde los géneros eran volcados a lo académico, lo cual parece ser coherente con las prácticas de lenguaje de los estudiantes durante sus pasos por la universidad. Ferreira (2015), quien estudió lo que los estudiantes leen y escriben en la UNILA, tuvo como una de las conclusiones de su análisis que uno de los géneros más solicitados por los profesores de la universidad es el género resumen, pues de esa manera pretenden comprobar la comprensión de lectura en los alumnos.

Se espera que el presente análisis pueda contribuir a debates sobre el papel de la enseñanza y de la evaluación de lenguas adicionales en el contexto universitario de la UNILA. 


\section{REFERÊNCIAS}

BAKHTIN, M.; VOLOSHINOV, V.N. 1929. Marxismo e filosofia da linguagem. Traducción por Michel L. y Yara F.V. Sao Paulo: Hucitec, 1988.

BELGIN, S.; LIETAER, B. Dinheiro para um mundo novo. Piseagrama, Belo Horizonte, número 10, p. 52-61, 2017. Disponible en: http://piseagrama.org/dinheiro-para-um-novo-mundo/. Acceso en: 13 mayo 2018.

BRANT, F. É fogo. Diário Impresso, Minas Gerais. Disponible en: http://impresso.em.com.br/app/noticia/cadernos/cultura. Acceso en: 21 de mayo 2018.

BRITTO, P.; REIS, L. Por pressão, planos de educação de 8 Estados excluem 'ideologia de gênero', Folha de S. Paulo, 25 junio 2015. Disponible en:http://www1.folha.uol.com.br/educacao/2015/06/1647528-porpressao-planos-de-educacao-de-8-estados-excluem-ideologia-degenero.shtml. Acceso en: 10 jun. 2018.

COSTA, M.A. Estruturalismo. In: MARTELOTTA, M. (Org.), 2008, Manual de linguística, São Paulo: Contexto, p. 113, 2008.

CRISTOVAO, L.V.L. O interacionismo socio-discursivo e o ensino de línguas com uma abordagem com base em gêneros textuais. In: CRISTOVAO, L.V.L. (Coord.), 2007, Modelos didáticos de gênero: uma abordagem para o ensino de lingua estrangeira. Londrina: UEL, p. 7, 2007.

DIAS, R. Critérios para a avaliação do livro didático (LD) de língua estrangeira (LE). In: DIAS, R; CRISTOVAO, L.V.L. (Orgs.), 2009, O livro didático de língua estrangeira: múltiplas perspectivas. Campinas: Mercado de Letras, p. 199, 2009.

DOWBOR, L. O valor econômico do tempo livre. Piseagrama, Belo Horizonte, n. 03, p. 14-17, 2011. Disponible en: http:/piseagrama.org/o-valor-economico-do-tempo-livre/. Acceso en: 12 mayo 2018.

ESTUDANTES do mundo embarcam na Ruta Inka. Carta Capital, 20 set. 2010.

Disponible en: https://www.cartacapital.com.br/internacional/estudantes-domundo-embarcam-na-ruta-inka. Acceso en: 21 mayo 2018. 
Evaluación de nivelación y la enseñanza de lenguas adicionales en el contexto UNILA | 209

FERREIRA, L.M.L. Práticas de leitura e escrita ao longo dos cursos de graduação na UNILA: subsídios para o ensino de línguas adicionais. Intercâmbio, São Paulo, v. 30, p.29-50, 2015.

Disponible

https://revistas.pucsp.br/index.php/intercambio/article/view/2511

5. Acceso en: 15 mayo 2018

LATUFF, C. Ferramentas de demarcação de terras. Disponible en: https://www.brasil247.com/pt/247/brasil/113966/O-violentomodelo-de-demarca\%C3\%A7\%C3\%A3o-de-terras-noPa\%C3\%ADs.htm. Acceso en: 20 mayo 2018.

LUPION, B. A relatora da ONU para direitos indígenas veio ao Brasil e se opôs a mudar a regra para demarcar terras. Nexo Jornal, 08 mayo 2016.

Disponible

en: https://www.nexojornal.com.br/expresso/2016/03/08/A-relatorada-ONU-para-direitos-ind\%C3\%ADgenas-veio-ao-Brasil-e-seop\%C3\%B4s-a-mudar-regra-para-demarcar-terras. Acceso en: 28 abr. 2018.

MARCUSCHI, L.A. Produção textual, análise de gêneros e compreensão. São Paulo: Parábola, 2008.

McNAMARA, T. Language assessment as social practice. In: Coloquio de Certificado de Español Lengua y Uso (CELU), IV, 2008, Buenos Aires.

OLIVEIRA, Gilvan de. Plurilinguismo no Brasil: repressão e resistência linguística. Synergies Brésil, Santa Catarina, n. 7, 2009, p. 19-26. Disponible en: https://gerflint.fr/Base/Bresil7/gilvan.pdf. Acceso en: 12 mayo 2018.

RAJAGOPALAN, Kanavilil. Língua estrangeira e auto-estima. In: . Por uma linguística crítica. Linguagem, identidade e questão ética. São Paulo: Parábola, 2003, p. 65-70.

Disponible

en: https://edisciplinas.usp.br/pluginfile.php/143904/mod resource/c ontent/1/Rajan\%20auto\%20estima\%202003.PDF. Acceso en: 12 mayo 2018.

SCARAMUCCI, M.V.R. O projeto Celpe-Bras no âmbito do Mercosul: contribuições para uma definição de proficiência comunicativa. In: ALMEIDA FILHO, J.C. (Org.), 1995, Português para estrangeiros: interface com o espanhol. Campinas: Pontes, p. 77, 1995.
UNIVERSIDAD
FEDERAL
$\mathrm{DE}$
INTEGRACIÓN LATINOAMERICANA-UNILA. 
Projeto de Desenvolvimento Institucional 2013-2017. UNILA: Foz do Iguaçu, 2013a. Disponible en: http://www.unila.edu.br/sites/default/files/files/PDI\%20UNILA $\% 20201$

3-2017.pdf. Acceso en: 02 de mayo 2018. _. Projeto Pedagógico do Ciclo Comum de Estudos. UNILA: Foz do Iguaçu, 2013b. Disponible en: https://unila.edu.br/sites/default/files/anexo_da_resolucao_009. 2013_-_ppc_ciclo_comum_de_estudos.pdf. Acceso en: 05 jun. 2018.

. Regulamento Biblioteca Paulo Freire PTI. UNILA: Foz do Iguaçu, 2014. Disponible en: https://www.unila.edu.br/sites/default/files/files/Regulamento\%2 OBiblioteca\%202014.pdf. Acceso en: 10 jun. 2018.

VINDAS, J.T. El enunciado en Bajtin: vivencia y sintaxis. Disponible en: https://www.alainet.org/es/active/19881. Acceso en: 08 de mayo 2018.

Recebido em: 26/03/2019

Aceito em: 16/04/2019 